\title{
EVALUATION OF NARROW-BAND UVB PHOTOTHERAPY FOR VITILIGO
}

Girish P.N1, Narendra J. Shetty², Vinma H. Shetty³, Sandhya I ${ }^{4}$, Umananda Mallya ${ }^{5}$, Ranjith Kumar Shetty B6, Vasudevan O.V7, I. Nagaraj Shetty ${ }^{8}$

\section{HOW TO CITE THIS ARTICLE:}

Girish PN, Narendra J Shetty, Vinma H Shetty, Sandhya I, Umananda Mallya, Ranjith Kumar Shetty B, Vasudevan OV, I. Nagaraj Shetty. "Valuation of narrow-band UV B photo therapy for vitiligo". Journal of Evolution of Medical and Dental Sciences 2013; Vol. 2, Issue 44, Nov ember 04; Page: 8591-8598.

\begin{abstract}
Vitiligo is an acquired de-pigmenting skin condition that results from destruction of melanocytes. There are very few studies from south India regarding the efficacy and safety of narrowband ultraviolet B (UVB) photo therapy in vitiligo which lead to the This prospective open non randomized study was conducted at a tertiary healthcare centre of south India between January 2011 and December 2011to determine the efficacy and safety of narrowband ultraviolet B (UVB) photo therapy in vitiligo. A total of 62 patients of vitiligo attending the dermatology outpatient department were enrolled in the study. Patients were treated with narrow band UVB phototherapy. Majority of our patients (29\%) were in the age group of 31-40 years. Duration of vitiligo varied from 4 months to 18 years, with a mean of 6.2 years. Percentage of body surface area involved by vitiligo varied from $2-80 \%$ with a mean of $12.8 \%$. Out of the various body sites, the most satisfactory repigmentation was seen on the face and the least was on the extremities. At the end of 6 months percentage area of re-pigmentation varied $60-90 \%$ on the face, $10-95 \%$ on upper limb, $15-90 \%$ on the trunk and $15-80 \%$ on lower limbs. Out of 62 patients, all had itching, which responded to oral antihistaminic. The phototoxic reactions were mild which were treated with topical steroid. This study emphasized the utility of narrow band UVB phototherapy as an effective modality of therapy for vitiligo.
\end{abstract}

KEYWORDS: Erythema; Melanocytes; Phototherapy; Vitiligo.

INTRODUCTION: Vitiligo is an acquired de-pigmenting skin condition that results from destruction of melanocytes. It is visibly striking in India because the depigmentation of vitiligo contrasts with the darker skin colour of Indians. Vitiligo remains the bugbear of dermatologists because of varied response to the therapy. Prevalence of vitiligo in India varied from $0.46 \%$ in Kolkata to $1.13 \%$ in Surat.1,2 No single method is completely successful or satisfactory. PUVA and topical corticosteroids are the most frequently used modalities. Surgical treatment helps in transferring normal skin or melanocytes to the vitiligo affected skin.

Narrow band UVB (NBUVB) phototherapy was first studied by Westerhof $\mathrm{W}$ and Nieuweboer-Krobotova. ${ }^{3}$ During recent times narrow band UVB phototherapy is being increasingly used for this disorder since the shorter wavelengths of UVB radiation have higher energy and are mostly responsible for the development of erythema, less erythema is induced following exposure to $311 \mathrm{~nm}$ UVB source (narrow band UVB) while treatment response remains high. There are only few published data available regarding the treatment for vitiligo. This study was conducted to determine the efficacy and adverse effects of narrow band UVB phototherapy.

MATERIALS AND METHODS: Patients with generalized and focal vitiligo presenting in the dermatology outpatient department of a tertiary healthcare centre of south India were the subjects 
of this study. A total of 62 patients were enrolled for the study. It was conducted for a period of one year from January 2011 to December 2011. In all these patients name, age, sex, occupation and stability were noted. Family history, any precipitating factors and previous therapies tried by the patients and their effects were noted. The patients were examined completely for the sites involved and type of vitiligo. The patients with one of the following were included in the study.

Patients with vitiligo of either sex who had, 1) Generalized vitiligo, involving $>10 \%$ of body surface area, 2) Generalized vitiligo, involving $<10 \%$ of body surface area with more than five sites involved excluding acral sites, lips and genitals or more than ten lesions (at distant sites) size of lesions more than one centimeter, 3) Segmental vitiligo, involving $>10 \%$ body surface area. All the patients with above 5 years of age and vitiligo which is stable for minimum period of one month were included in this study. Patients with lack of response to previous PUVA therapy, intolerance to psoralens were also included in the study. Patients with photosensitive disorders or history of cutaneous malignancy were excluded from the study. A washout period in which patient should be off other treatments in the form of systemic steroids / PUVA for 1 month and topical steroids for 15 days was recommended. Pretreatment \& post treatment photographs (3 \& 6 months) were taken. Parental consent was obtained for the children and informed consent was taken from the rest.

Whole body narrow band phototherapy (Dermaindia) unit with twelve narrow band fluorescent tubes (Philips TL 100W/01) measuring 6 feet in length with a spectrum of 310 to $315 \mathrm{~nm}$ and a maximum emission wavelength of $311 \mathrm{~nm}$ was used for the treatment. Narrow band UVB therapy was given twice weekly even while ensuring that it was not administered on two consecutive days. During the treatment the eyes were protected by UV-blocking goggles. If significant depigmentation was present on the eyelids and patients or their guardians insisted on treating these areas, patients were told to keep their eyes shut during the treatment and not to wear goggles. All the patients kept their clothing on to shield the genitals from narrow band UVB exposure.

The initial starting dose was $100 \mathrm{~mJ}$ (whole body) and the dose was subsequently increased by $20 \%$ each time, till the development of persistent erythema (in the vitiligo patches) i.e. just perceptible erythema or an erythema with sharp margins after 24 hours of exposure and persisting at 72 hours after the exposure. Additional exposure of $10 \%, 20 \%$, and $30 \%$ of the whole body dose was given to the upper and lower extremities in successive sittings and was thereafter maintained at $30 \%$ of the corresponding whole body dose. If erythema was painful, one dose was omitted and the patient was reassessed after 72 hours. The persistent erythema dose was continued for 6 months. The total duration of the treatment was 6 months after achieving persistent erythema dose in a vitiligo patch.

RESULTS: A total number of 62 patients were included in the study. Table 1 gives age wise distribution of the patients. The age of the patients in this study varied from 6-60 years and mean age was 29 years + 12.8 standard deviation. Majority of the patients (29\%) were in age group of 3140 years. Out of 62 patients 28(45\%) were males and 34(55\%) were females. Duration of vitiligo varied from 4 months to 18 years, with a mean of 6.2 years. None of the patients had a family history of vitiligo. Stable means no expansion of existing lesions or no appearance of new lesions. Duration of stability varied from 1 month to 5 years with a mean of 9.4 months. Percentage of body surface 
area involved by vitiligo varied from $2-80 \%$ with a mean of $12.8 \%$ (Graph 1). Out of 62 patients of vitiligo, 56(90.4\%) were of generalized type and six (9.6\%) were of focal type.

Out of the various body sites, the most satisfactory re-pigmentation was seen on the face and the least was on the extremities. Out of total 62 patients, 34 showed first sign of re-pigmentation after 6-10 sittings of narrow band UVB phototherapy. At the end of 3 months, the percentage area of repigmentation varied from $30-70 \%$ on the face, $5-80 \%$ on upper limbs, $10-80 \%$ on the trunk and $10-60 \%$ on lower limbs (Graph 2). At the end of 6 months percentage area of re-pigmentation varied $60-90 \%$ on the face, $10-95 \%$ on upper limb, $15-90 \%$ on the trunk and $15-80 \%$ on lower limbs (Table 2, Graph 2). Out of the 62 patients, two stopped the treatment after 31 and 32 sittings due to financial compulsions and another two patients stopped after 18 and 24 sittings due to the poor response and constraints in visiting the hospital, and four patients failed to show any repigmentation at the end of three month s of therapy.

The persistent erythema dose (PED) varied from $120 \mathrm{~mJ} / \mathrm{sq} \mathrm{cm}$ to $1278 \mathrm{~mJ} / \mathrm{sq} \mathrm{cm}$ with a mean of $531.7 \mathrm{~mJ} / \mathrm{sq} \mathrm{cm}$ (Table 3). The cumulative dose varied from $7.1 \mathrm{~J} / \mathrm{sq} \mathrm{cm}$ to $61.8 \mathrm{~J} / \mathrm{sq} \mathrm{cm}$ with a mean of $26.65 \mathrm{~J} / \mathrm{sq} \mathrm{cm}$. Out of 62 patients, all had itching, which responded to oral antihistaminic (Table 4). The phototoxic reactions were mild which were treated with topical steroid. No correlation could be found with regards to duration of disease and re-pigmentation. Best results of re-pigmentation were obtained when the disease was stable for 1 month to 6 months. It was clinically observed that among patients with less than $10 \%$ body surface area involvement and having lesser re-pigmentation $(<30 \%$ and $30-50 \%)$ had smaller patches mainly on areas of bony prominence and less hairy region.

DISCUSSION: Phototherapy continues to be one of the first lines of treatment in vitiligo. Now NBUVB is preferred as it is safe and effective in treating vitiligo even in pregnancy and children.4,5,6 The age of the patients in this study varied from 6-60 years and the mean age was 29.9 years. Majority of the patients (29\%) were in age group of 31-40 years. Four patients were aged between 5-10 years. The age distribution in the study by Kishan kumar et $\mathrm{al}^{7}$ and Westerhof et al was similar to our study. ${ }^{8}$ Duration of vitiligo in the present study the duration of vitiligo varied from 4 months to 18 years with a mean of 6.2 years. The average duration of the disease in the Westerhof study was 13.3 months and in the Njoo's study it was 4 years.8,9

The duration of stability in our study varied from 1 month to 5 years the average being 9.4 months. In the study by Westerhof et al all the patients had active vitiligo. ${ }^{8}$ Out of the 51 patients in Njoo's study, 8 had active disease in the past 6 weeks, 20 in the past 3 months, 16 in the past 6 months, 5 in the past year and 2 were stable for at least 1 year. ${ }^{9}$ Njoo's study also revealed that $80 \%$ of the patients stabilized after 1 year of therapy while in the current study approximately $90 \%$ of the patients stabilized after 6 months of therapy. ${ }^{9}$ Percentage of body surface area involvement varied from $2-80 \%$ with a mean of $12.8 \%$ in our patients. The extent of depigmentation in Westerhof's ${ }^{8}$ study varied from $10-50 \%$. In Njoo's study the mean percentage of depigmentation was $15.9 \% .{ }^{9}$ Thus the severity of the disease in the present study correlates well with that of Njoo's study. 9

Out of the 44 patients in our study, who had facial lesions of vitiligo, $22(50 \%)$ patients had first re-pigmentation on the face. A significant proportion i.e. 58.6\% of the patients had first re-pigmentation after 6 to 19 sittings. $34.5 \%$ of the patients had initial repigmentation after 1-5 sittings. Earliest re-pigmentation was seen after $3^{\text {rd }}$ sitting in our patients. In 
the Westerhof's study, re-pigmentation started about 6 weeks after the initiation of treatment. ${ }^{8}$ In the current study re-pigmentation had started earlier than the Westerhof's study. ${ }^{8}$ This may by virtue of the darker skin type of Indian patients, which may respond more favorably than lighter skin types.6,10,11

In our study at the end of 3 months after achieving the persistent erythema, a significant proportion $(54.5 \%)$ of the patients showed $45-60 \%$ of re-pigmentation on the face. In the Westerhof's study, $48 \%$ of the patients showed $25-75 \%$ re-pigmentation. ${ }^{8}$ In the current study at the end of 6 months, percentage area of re-pigmentation varied from $60-90 \%$ on the face which was observed in other studies also. Thus the most gratifying response was achieved with lesions located on the face and trunk. Lesion located on the breast, back, arms and legs responded with more than $75 \%$ re-pigmentation while the joints such as knee and elbows seldom showed more than $75 \%$ repigmentation. Most lesions on the hands, digits, feet and toes only showed minor to no repigmentation. These findings are consistent with the Njoo's and Westerhof's studies.8,9 In Njoo's study $72 \%$ of lesions on the face and $74 \%$ of lesions on the neck showed more than $75 \%$ repigmentation at the end of 1 year. ${ }^{28}$ Hamzavi I et al noted best response over legs followed by trunk, arms, hands and feet (without considering face).12

Persistent erythema dose is the lowest radiation exposure to ultraviolet radiation sufficient to produce either, just perceptible erythema on exposed lesional skin after 24 hours or an erythema with sharp margins after 24hours and persisting at 72 hours after the exposure ${ }^{13}$. The persistent erythema dose in the present study varied from $120 \mathrm{~mJ} / \mathrm{sq} \mathrm{cm}$ to $1278 \mathrm{~mJ} / \mathrm{sq} \mathrm{cm}$ with a mean of $531.7 \mathrm{~mJ} / \mathrm{sq} \mathrm{cm}$. In the study by Westerhof et al ${ }^{8}$ minimal erythema dose of lesional skin was between 200 and $450 \mathrm{~mJ} / \mathrm{sq} \mathrm{cm}$. In Westerhof's ${ }^{8}$ study the patients were from Netherlands, where the sun exposure is less. While in India, higher sun exposure may be responsible for more, natural photo protective mechanism leading to higher persistent erythema dose as seen in our patients. Serish and Srinivas CR reported that $300 \mathrm{~mJ} / \mathrm{sq} . \mathrm{cm}$ (NBUVB) was the mean minimal erythema dose (MED) for the Indian skin. ${ }^{14}$

The cumulative dose in the current study varied from $7.1 \mathrm{~J} / \mathrm{sq} \mathrm{cm}$ to $61.8 \mathrm{~J} / \mathrm{sq} \mathrm{cm}$ with a mean of $26.65 \mathrm{~J} / \mathrm{sq} \mathrm{cm}$. In the Westerhof's study cumulative dose at 12 months varied from 9.58 to $128.01 \mathrm{~J} / \mathrm{sq} \mathrm{cm}$ with a mean of $32.34 \mathrm{~J} / \mathrm{sq} \mathrm{cm}^{8}$ In the Njoo's study average cumulative dose was 91.3 J/sq cm at 12 months of treatment. ${ }^{9}$ Cumulative dose reported by Kishan Kumar YH et al was $46.8+25.2 \mathrm{~J} / \mathrm{sq} \mathrm{cm}$ to achieve $25-75 \%$ of re-pigmentation. ${ }^{7}$ Thus Indian skin requires less number of exposures to NBUVB to achieve re-pigmentation. $6,10,11$

Out of the 62 patients in the current study, all the patients had itching, which was treated with emollients and some with an oral antihistaminic. It usually started after 2-5 sittings after initiating the ther apy. Itching was also reported by Westerhof et al, Njoo et al and Dogra S but in the Njoo's study 8\% and Kishan Kumar YH et al 7\% of the patients had itching. 7,8,9,11 The higher incidence of itching in the study may be related to the higher dose of irradiation. Tanning was seen in 30 of our patients. Most of these patients received a higher dose of irradiation. Phototoxic reaction was seen in 10 patients in the current study, which was mild and was treated with topical steroid with omission of the irradiation till tender erythema disappears. In the Njoo's study there was no phototoxic reaction. In our study the irradiation dose that was maintained was persistent erythema dose (PED), rather than minimum erythema dose in the Westerhof's and Njoo's studies.8,9 There was only a very narrow range between persistent erythema dose and the phototoxic dose. Thus this may 
explain the cause of higher phototoxic reaction in the current study. Four patients developed photo hardening (thickening of skin on the photo exposed skin) over the vitiligo patches on the knuckles. In the Westerhof's study there was no hyperkeratosis even after long-term irradiation. ${ }^{8}$ Herpes labialis was seen in two of our patients which was not seen in the Westerhof's and Njoo's studies.8,9

No correlation could be found with regards to duration of disease and re-pigmentation in the current study, which is consistent with Njoo's study where also no such correlation could be found. ${ }^{9}$ Best results were obtained when the disease was stable for 1 month to 6 months. Our patients with less than $10 \%$ body surface area involvement and having lesser re-pigmentation $(<30 \%$ \& $30-50 \%$ re-pigmentation) had smaller patches mainly on areas of bony prominence \& less hairy regions. Thus even the small vitiligo patches on the bony prominences and on less hairy regions show poor re-pigmentation. No significant relationship was found between re-pigmentation grades and the variables age, sex and type of vitiligo in the present study, which was consistent with the Njoo's study. ${ }^{9}$ Thus NB-UVB is the most cost effective among the UV based therapies. ${ }^{15}$

CONCLUSIONS: Narrow band UVB phototherapy is an effective modality of therapy for vitiligo. Adverse effects are minimal and transient. At higher doses UVB also induces tanning. In view of continuing and incomplete re-pigmentation at the end of 6 months of phototherapy it may be advisable to continue the treatment further, up to a year. Shorter treatment sessions and twiceweekly exposure is a convenient O.P.D. basis therapy, are particularly suited to a busy metropolis. Narrow band UVB phototherapy improves quality of life particularly in children, compared to PUVA therapy, which required outdoor activity restriction to reduce psoralen induced photo toxicity. Cost of therapy may limit its widespread use in developing countries. Being a very useful treatment option for vitiligo, which is a cosmetic embarrassment to a disaster in dark skinned patients; further studies are required with long-term follow up for optimum duration of therapy, pigment retention after stopping treatment and long-term side effects.

ACKNOWLEDGEMENT: We thank immensely Mrs.Manjula Anil (bio-statistician) for her help in statistical analysis of the study.

\section{REFERENCES:}

1. Das SK, Majumder PP, Chakraborty R, Majumdar TK, Haldar B. Studies on vitiligo, I: Epidemiological profile in Calcutta, India. Genet Epidemiol 1985;2:71-8.

2. Mehta NR, Shah KC, Theodore C, Vyas VP, Patel AB. Epidemiological study of vitiligo in Surat area, South Gujarat. Indian J Med Res 1973;61:145-54.

3. Westerhof W, Nieuweboer-Krobotova L. Treatment of vitiligo with UV-B radiation vs. psoralen plus UV-A. Arch Dermatol 1997;133:1525-8.

4. Hercogova J, Buggiani G, Prignano F, Lotti T. A rational approach to the treatment of vitiligo and other hypomelanoses: Pigmentary disorders. Dermatol Clin 2007;25:383-92.

5. Yones SS, Palmer RA, Garibaldinos TM, Hawk JL. Randomized double-blind trial of treatment of vitiligo: Efficacy of psoralen-UV-A therapy vs Narrowband-UV-B therapy. Arch Dermatol 2007;143:578-84.

6. Kanwar AJ, Dogra S. Narrow-band UVB for the treatment of generalized vitiligo in children. Clin Exp Dermatol 2005;30:332-6. 
7. Kishan Kumar YH, Rao GR, Gopal KV, Shanti G, Rao KV. Evaluation of narrow-band UVB phototherapy in 150 patients with vitiligo. Indian J Dermatol Venereol Leprol 2009;75:162-6

8. Westerhof W, Nieuweboer - Krobotova L: Treatment of vitiligo with UVB radiation vs topical psoralen plus UV-A. Arch Dermatol 1997;133: 1525 - 1528

9. Njoo MD, Bos JD, Westerhof W. Treatment of generalized vitiligo in children with narrowband (TL-01) UVB radiation therapy. J Am Acad Dermatol 2000;42:245-53.

10. Kanwar AJ, Dogra S, Prasad D, Kumar B. Narrow-band UVB for the treatment of vitiligo: An emerging effective and well-tolerated therapy. Int J Dermatol 2005;44:57-60.

11. Dogra S, Prasad D. Combination of narrow band UVB and topical calcipotriene in vitiligo. Arch Dermatol 2003;139:393.

12. Hamzavi I, Jain H, McLean D, Shapiro J, Zeng H, Lui H. Parametric modeling of narrowband UV-B phototherapy for vitiligo using a novel quantitative tool: The Vitiligo Area Scoring Index. Arch Dermatol 2004;140:677-83.

13. Cripps DJ, Lowe NJ, Lerner AB. Action spectra of topical psoralens: a re-evaluation. British Journal of Dermatology 1982;107:77-82.

14. Serish, Srinivas CR. Minimal erythema dose (Med) to narrow band ultraviolet - B (NB-UVB) and broad band ultraviolet-B (BB-UVB): A pilot study. Indian J Dermatol Venereol Leprol 2002;68:63-4.

15. Hamzavi IH, Lim HW,Syed ZU. Ultraviolet-based therapy for vitiligo: What's new?. Indian J Dermatol Venerol Leprol 2012;78:42-8.

\begin{tabular}{|c|c|}
\hline Age group (years) & No. of patients (\%) \\
\hline $5-10$ & $4(6.6)$ \\
\hline $11-20$ & $14(22.5)$ \\
\hline $21-30$ & $12(19.3)$ \\
\hline $31-40$ & $18(29)$ \\
\hline $41-50$ & $12(19.3)$ \\
\hline $51-60$ & $2(3.3)$ \\
\hline Total & $62(100)$ \\
\hline
\end{tabular}

Table 1: Age wise distribution of the study subjects

\begin{tabular}{|c|c|}
\hline Results & Number of Patients (\%) \\
\hline Poor $(<30 \%$ re-pigmentation $)$ & $2(3.2 \%)$ \\
\hline Fair (30-50\% re-pigmentation) & $12(19.3 \%)$ \\
\hline Good (50-75\% re-pigmentation) & $40(64.5 \%)$ \\
\hline Excellent (> 75\% re-pigmentation) & $0(0 \%)$ \\
\hline Failure (No response at the end of 3 months) & $4(6.5 \%)$ \\
\hline Failure to follow up & $4(6.5 \%)$ \\
\hline Total & 62 \\
\hline
\end{tabular}




\begin{tabular}{|c|c|}
\hline PED in mJ & Number of patients (\%) \\
\hline $0-150$ & $14(22.6)$ \\
\hline $150-300$ & $6(9.7)$ \\
\hline $300-450$ & $16(25.8)$ \\
\hline $450-600$ & $8(12.9)$ \\
\hline $600-750$ & $10(16.1)$ \\
\hline $750-900$ & $4(6.5)$ \\
\hline $900-1050$ & $0(0)$ \\
\hline $1050-1200$ & $2(3.2)$ \\
\hline $1200-1350$ & $2(3.2)$ \\
\hline Total & $62(100 \%)$ \\
\hline
\end{tabular}

\begin{tabular}{|l|c|}
\hline \multicolumn{1}{|c|}{ Adverse reaction } & No. of patients (\%) \\
\hline Itching & $62(100)$ \\
\hline Tanning & $30(48.3)$ \\
\hline Phototoxic reaction & $10(16.1)$ \\
\hline Photo hardening & $4(6.4)$ \\
\hline Herpes labialis & $2(3.2)$ \\
\hline
\end{tabular}

Table 3: Persistent ery thema dose (PED) in

TABLE 4: Adverse reactions following NBUVB phototherapy among the study subjects $(n=62)$

$\mathrm{mJ} / \mathrm{cm}^{2}$ among the study subjects $(\mathrm{n}=62)$

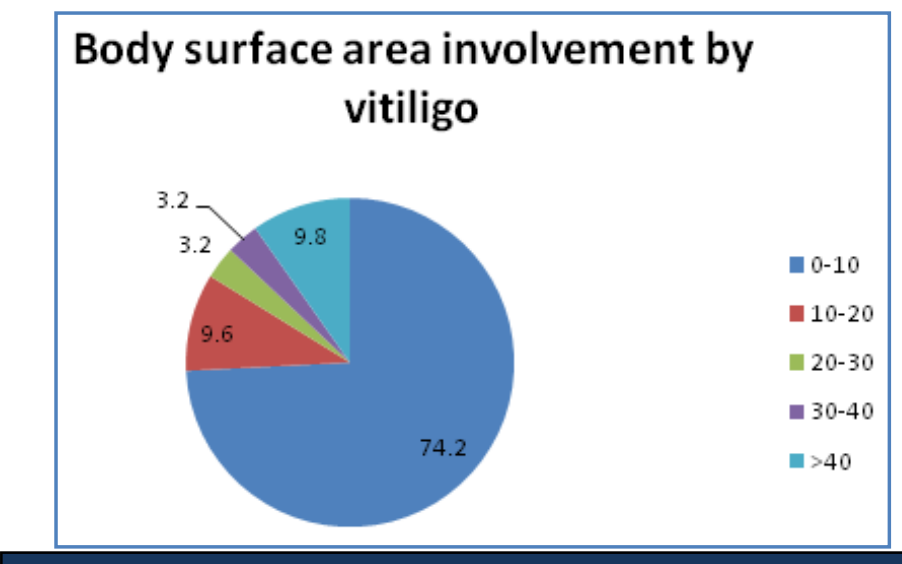

Graph 1: Percentage of body surface area involvement

by vitiligo among the study subjects $(n=62)$

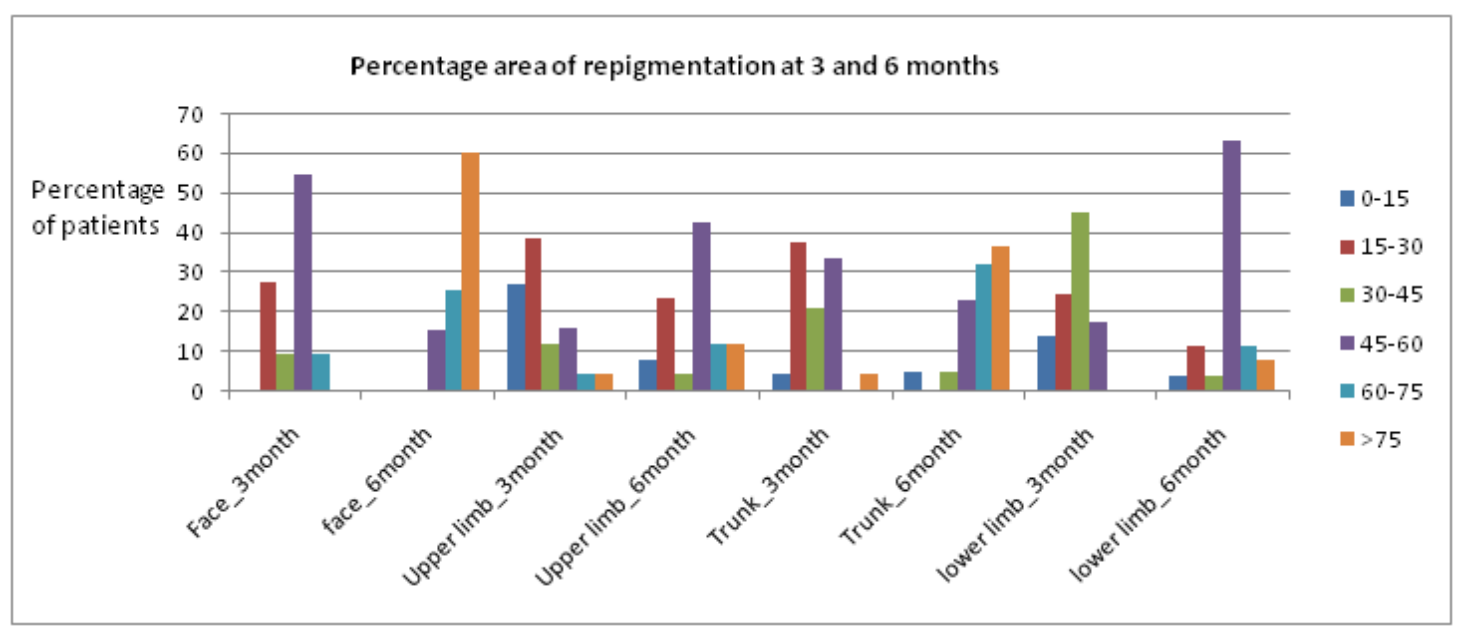

Graph 2: Area of re-pigmentation at 3 and 6 months 


\section{AUTHORS:}

1. Girish P.N.

2. Narendra J. Shetty

3. Vinma H. Shetty

4. Sandhya I.

5. Umananda Mallya

6. Ranjith Kumar Shetty B.

7. Vasudevan O.V.

8. I. Nagaraj Shetty

\section{PARTICULARS OF CONTRIBUTORS:}

1. Professor, Department of Dermatology, A. J. Institute of Medical Sciences \& Research Centre, Mangalore.

2. Professor \& H.O.D., Department of Dermatology, A. J. Institute of Medical Sciences \& Research Centre, Mangalore.

3. Associate Professor, Department of Dermatology, A. J. Institute of Medical Sciences \& Research Centre, Mangalore.

4. Assistant Professor, Departm ent of Pathology, A. J. Institute of Medical Sciences \& Research Centre, Mangalore.
5. Professor, Department of Orthopaedics, A. J. Institute of Medical Sciences \& Research Centre, Mangalore.

6. Professor, Department of General Surgery, A. J. Institute of Medical Sciences \& Research Centre, Mangalore.

7. Associate Professor, Department of Psychiatry, A. J. Institute of Medical Sciences \& Research Centre, Mangalore.

8. Professor, Department of General Medicine, A. J. Institute of Medical Sciences \& Research Centre, Mangalore.

\section{NAME ADDRESS EMAIL ID OF THE CORRESPONDING AUTHOR:}

Dr. Girish P.N.

Professor, Department of D erm atology,

A. J. Institute of Medical Sci ences \& Research Centre, Mangalore.

Email - pattegiri@yahoo.co.in

Date of Submission: 22/10/2013.

Date of Peer Review: 23/10/2013.

Date of Acceptance: 27/10/2013.

Date of Publishing: 30/10/2013 